\title{
"Tinea Nigra" no Amazonas
}

\author{
Ozório José de Menezes Fonseca (*) \\ SIMÃo ARÃo PECHER (**)
}

\section{SiNOPSE}

Os autores descrevem um caso de Tinea Nigra localizado sôbre um hemangioma plano, na palma da mão direita de uma paciente que tinha, concom1tantemente, Estrófula alimentar. Embora não seja essa a primeira observação dessa dermatose no Estado do Amazonas, êsse é, no entanto, o primeiro caso descrito, com a identificação sistemática do agente etiológico. O fungo isolado no meio de Sabouraud-dextroseagar, é classificado pelos Autores como Pullularia wernecki (Horta) de Vries.

\section{REGISTRO DO CASO}

J. B. A., amazonense, solteira, 19 anos de idade, residente em Manaus, Amazonas, apresenta mácula escura de $2,5 \mathrm{~cm}$ de diâmetro, superfície plana, puntiforme, localizada no bor. do de um hemangioma plano na mão direita (fig. 1).

A paciente diz possuir essa mancha há cêrca de 3 anos, sem contudo dar maior importân- cia ao fato. Não sabe exatamente, como nem onde observou pela primeira vez a presença da mancha.

O exame físico apresenta lesöes hipercrómicas, conglomeradas, lenticulares, dando um aspecto de "mancha", de mais ou menos $2 \times 2 \mathrm{~cm}$, localizada na região hipotenar da palma direita, próximo de uma lesão eritematosa de mais ou menos $3 \times 3 \mathrm{~cm}$ (Hemangioma plano), sem prurido, sem dor, discretamente áspera.

A paciente procurou recursos médicos devido a outro problema evidenciado por lesões eritemato - pápulo - vésico - pustulosas, m i c r ohemorrágicas, nas pernas e discretamente nos braços, pruriginosas, dolorosas, com adenopatias satélites inguinais, diagnosticado por um dos autores (Pecher), como Estrófula alimentar. Apenas casualmente, foi constatada a lesão fúngica, para a qual, o tratamento à base de Griseofulvina foi inócuo.
Fig. 1 - 'Tinea Nigra', sô. bre hemangioma plano (Foto O. J. M. Fonseca)

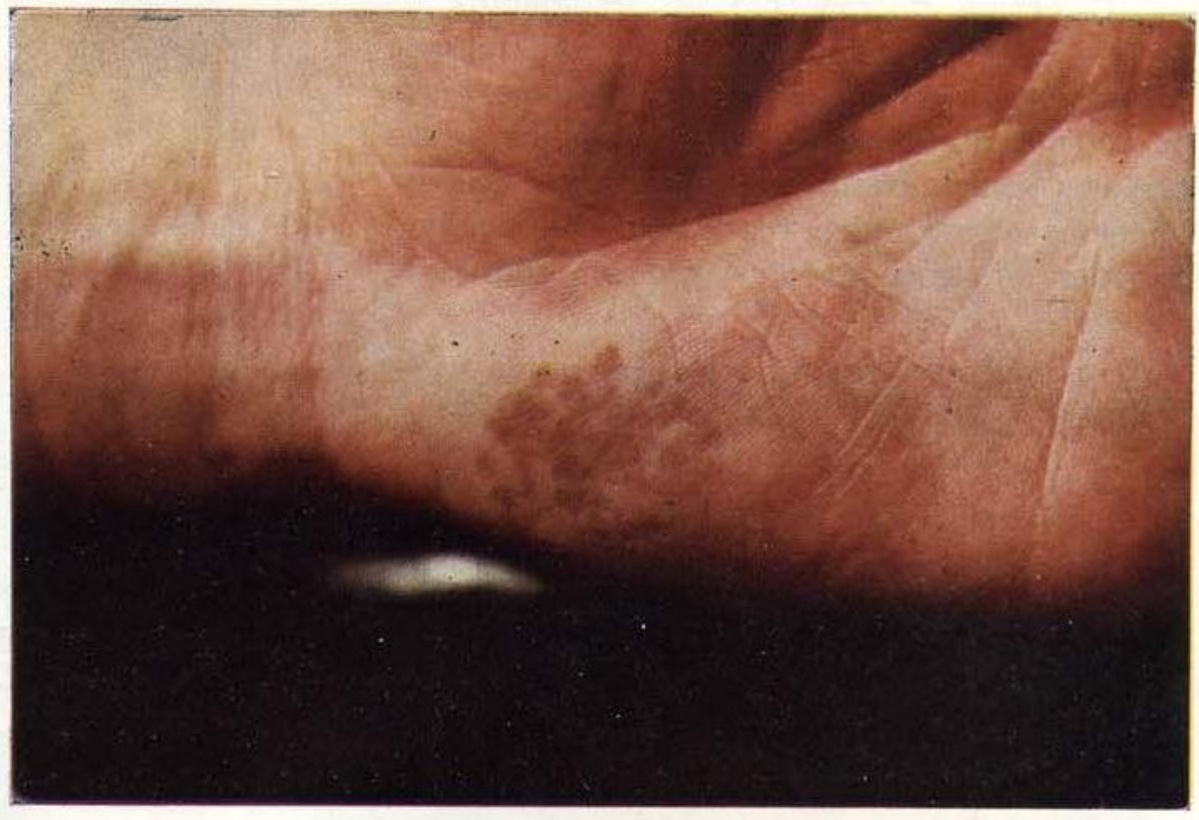

(*) - Instituto Nacional de Pesquisas da Amazônia, Bolsista do Conselho Nacional de Pesquisas.

(**) - Da Cadeira de Dermatologia da Faculdade de Medicina da Universidade do Amazonas. 


\section{ASPECTOS MICOLÓGICOS}

As escamas epidérmicas retiradas do local e observadas microscopicamente entre lâmina e lamínula, tendo como clareador o Hidróxido de Potássio a $20 \%$, revelaram abundantes hifas marrons, septadas, irregulares, ramificadas.

A cultura no meio de Sabouraud-dextroseagar contendo Cloranfenicol, depois de oito dias à temperatura ambiente, apresentou colonias negras, brilhantes, leveduriformes, de $1 \mathrm{~cm}$ de diâmetro. Aos 30 dias, essas colonias mediam 3 a $3,5 \mathrm{~cm}$ de diâmetro e estavam recobertas por micélio penugento, verde-negro (fig. 2).

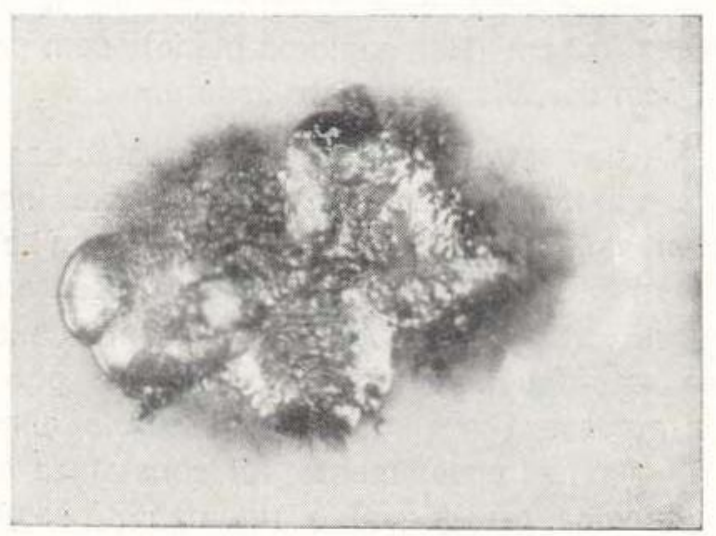

Fig. 2

O exame microscópio de fragmentos da cultura e de cultivos em lâmina no meio de Sabouraud, apresenta aspectos distintos entre as colônias jovens e as colônias velhas. Nas colônias jovens, observa-se a presença de células globosas a ovóides, reproduzindo-se por brotamento simples e por divisão direta (fig. 3 ).

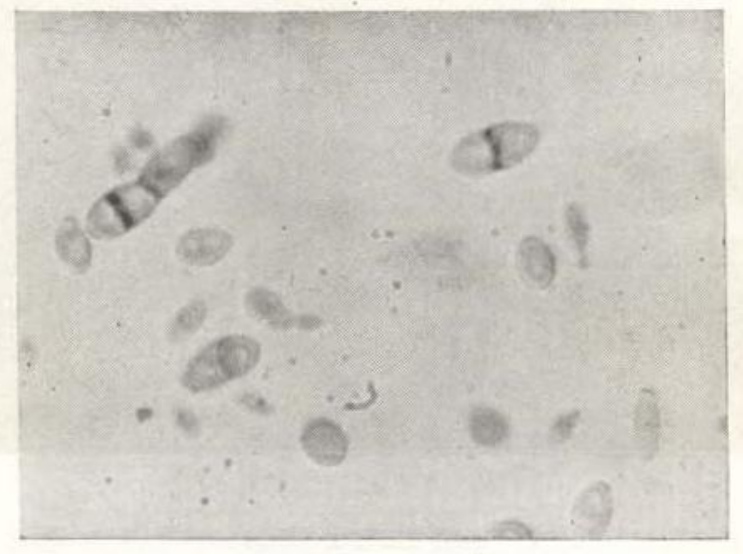

Fig. 3
Nas colônias velhas, o micélio é filamentoso, septado, constituído de células de forma e tamanho variáveis, com formaçăo de clamidósporos intercalares até $7 \mu$ de diâmetro. A reprodução é feita por conídios subglobosos a elípticos $(3-5 \times 4-10 \mu)$ agrupados em cachos no ápice de conidóforos pequenos, laterais (fig. 4), ou ainda por conídios sésseis, localizados ao longo das hifas (fig. 5).

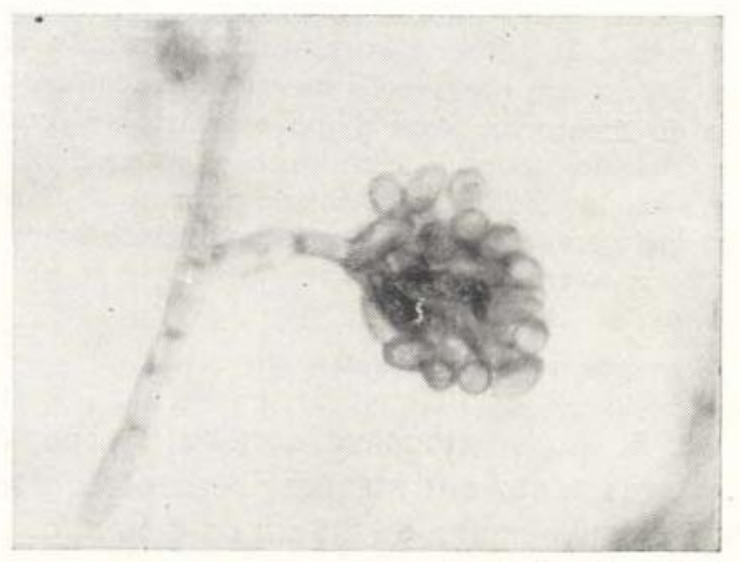

Fig. 4

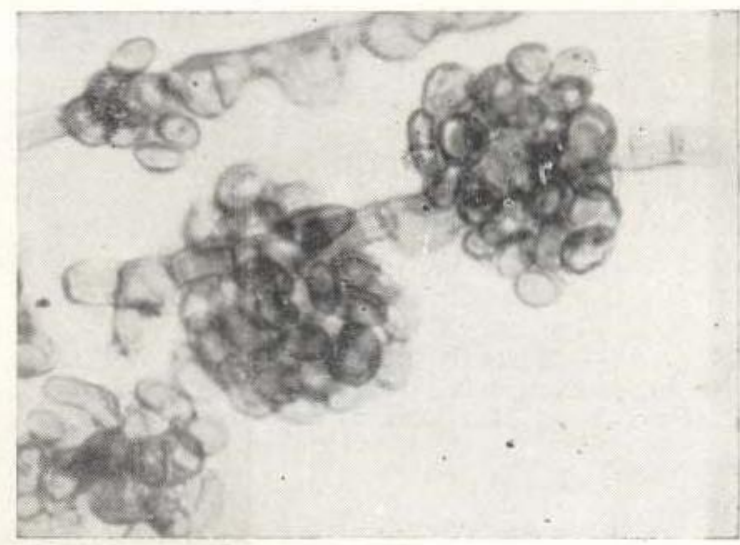

Fig. 5

Dada a grande semelhança micromorfológica com outras entidades fúngicas, os autcres analisaram as características fisiológicas da "cepa" (Tabela I) e, aliando essas propriedades aos caracteres morfológicos, classificam o fungo dentro do binômio Pullularia wernecki (Horta) de Vries, 1952. 


\begin{tabular}{|c|c|c|c|c|c|c|c|c|c|c|c|c|c|}
\hline \multicolumn{11}{|c|}{ Fermentação de carbohidratos } & & \multicolumn{2}{|c|}{ Pigmento } \\
\hline 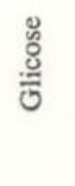 & 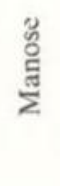 & 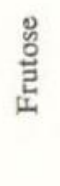 & 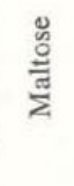 & 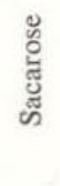 & 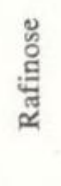 & : & 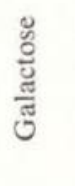 & 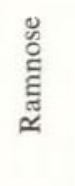 & 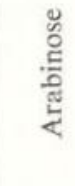 & 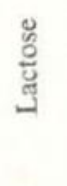 & 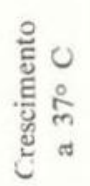 & 急总 & 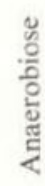 \\
\hline- & - & - & - &. & - & - & - & - & - & - & + & - & + \\
\hline
\end{tabular}

\section{COMENTÁRIO}

A Tinha Negra foi observada pela primeira vez em Manaus por Moraes \& Ferreira (1967) não havendo contudo, registro detalhado dos casos. Apenas a citação dessa dermatose como uma das micoses superficiais da Amazônia. Apesar dos anos decorridos desde as observações de Moraes \& Ferreira (1967) e o presente registro, sem que outros casos fôssem assinalados, é de se supor que a Tinea. Nigra seja mais freqüente nessa região. Costa \& Costa (1960 e 1961) descreveram em Belém, Estado do Pará, casos de Tinha Negra tanto de localização palmar como plantar. Não há dúvida de que essa dermatomicose ocupa, do ponto vista epidemiológico, lugar de pequeno destaque entre as infecções fúrigicas da Amazônia, ficando o seu interêsse fundamentado apenas na sua etiologia.

O estudo da amostra isolada do caso aqui descrito, baseado nos trabalhos de Belfort et alii (1960), Lacaz (1967), Wynne \& Gott (1956) e Zapater (1965), revelou que o fungo agente da Tinea Nigra deve ser enquadrado no gênero Pullaria espécie wernecki.

\section{SUMMARY}

The Authors describe a case of Tinea Nigra, located on a plane hemagioma, on the right hand palm of a patient who, at the same time was suffering from alimentary Estrophola.

Altough this may not be first observation of this skin disease in the State of Amazonas, it is however, the first case description, accompanied by the systematical identification of the etiological agent,

The fungus, isolated through Sabouruad-dextrose-agar, is classified by the Authors as being Pullu laria wernecki (Horta) de Vries.

\section{BIBLIOGRAFIA CITADA}

BELFORT, E. ET ALII

1960 - Tinea Nigra, registro do primeiro caso em São Paulo, com descrição do agente eitológico. Rev. paul. Med., 57 : 386-397.

Costa, C. A. \& Costa, L. A.

1960 - Tinha Negra Palmar em Belém do Pará. Rev. esp. Saúde públ., Rio de Janeiro, 11 : 219-244.

1961 - Localização interessante de Tinha Negra. Anais bras. Derm. sif., 36: 15-17.

LACAZ, C. DA S.

1967 - Compêndio de micologia médica. São Paulo, Sarvier.

Moraes, M. A. P. de \& Ferreira, J. L. da S.

1967 - Micoses superficiais e profundas na Amazônia. Atas Simp. sôbre Biota Amazônica, 6: (Patologia): 189-202.

WYNNE, E. S. \& GoTT, C. L.

1956 - A proposed revision of the genus Pullularia. J. gen. Microbiol., 14: 512-519.

ZAPATER, R. C.

1965 - Atlas de diagnóstico micológico (aplicacion del laboratorio). Buenos Aires, "El Ateneo" 